\title{
Temperature Dependence of Limiting Viscosity Number and Radius of Gyration for Cellulose Dissolved in Aqueous 8\% Sodium Hydroxide Solution
}

\author{
Kenji KAMIDE, Masatoshi SAITo, and Keisuke KowSAKA \\ Asahi Chemical Industry Co., Ltd., \\ Fundamental Research Laboratory of Fiber and Fiber Forming Polymers, \\ 11-7, Hacchonawate Takatsuki, Osaka 569, Japan
}

(Received April 15, 1987)

\begin{abstract}
A regenerated cellulose with a weight-average molecular weight $\bar{M}_{w}$ of $8.0 \times 10^{4}$ was dissolved in $8 \mathrm{wt} \%$ aq sodium hydroxide $(\mathrm{NaOH})$ solution under adequately chosen conditions. The solution viscosity and light scattering measurements were carried out over a wide range of temperature $T$ ranging 0.6 to $46^{\circ} \mathrm{C}$ and 3.5 to $45^{\circ} \mathrm{C}$, respectively. The apparent $\bar{M}_{w}$ of the sample, determined by the light scattering in aq $\mathrm{NaOH}$, remained practically constant $\left(7.9 \times 10^{4}\right)$ at $10 \leq T \leq 45^{\circ} \mathrm{C}$, being in good agreement with the true $\bar{M}_{w}\left(8.0 \times 10^{4}\right)$, evaluated by the light scattering method in cadoxen. This means that cellulose dissolves molecularly in $8 \mathrm{wt} \%$ aq $\mathrm{NaOH}$. This solution was found to be a Flory theta solvent at about $40^{\circ} \mathrm{C}$, at which the second virial coefficient $A_{2}$ vanishes. The Flory viscosity parameter $\Phi$ was $c a .1 / 5$ the theoretical value $\left(2.87 \times 10^{23}\right)$ of the unperturbed undraining chain, indicating that cellulose is a partially free draining chain when dissolved in aq $\mathrm{NaOH}$. The unperturbed chain dimension $A$ decreased with $T$. The flexibility of the cellulose chain in aq $\mathrm{NaOH}$ lies between those in cadoxen and iron sodium tartarate and all of them are classified as semi-flexible. The negative temperature dependence of the limiting viscosity number $[\eta]$ was explained as mainly due to a large negative $\partial A / \partial T$.

KEY WORDS Cellulose / Aqueous Alkali Solution / Light Scattering Viscosity / Temperature Dependence / Unperturbed Chain Dimension / Flory's Theta Temperature /
\end{abstract}

Recently Kamide and his collaborators ${ }^{1-3}$ analysed in a very systematic manner the experimental data of solution viscosity, light scattering, sedimentation and diffusion for cellulose and its derivative (CD) solutions, concluding for the molecular properties of these polymers that the excluded volume effect is extremely small and the unperturbed chain dimension A varies depending on the polarity of the solvent, but in common solvents cellulose chain behaves semiflexibly. However, as far as CD solutions are concerned, the above conclusions were derived at a constant temperature, near room temperature and only fragmental knowledge of the temperature dependence of the molecular characteristics is obtained up to now. For example only a few theta solvents were determined for $\mathrm{CD}$ as the solvent, in which $A_{2}$ becomes zero; cellulose tricarbanirate $(\mathrm{CTC})$-anisole $\left(\Theta=94^{\circ} \mathrm{C}\right){ }^{4}$ CTC-hexanol $\left(73^{\circ} \mathrm{C}\right)$, and cellulose diacetate (CDA)-2-butanone $\left(50^{\circ} \mathrm{C}\right) .^{5,6}$ Another example is two conflicting molecular explanations for a significantly negative temperature coefficient of the limiting viscosity number of CD solutions around room temperature. ${ }^{7-21}$ Suzuki et al. ${ }^{21}$ determined directly by experiments the temperature dependences of $[\eta], z$ average radius of gyration $\left\langle S^{2}\right\rangle_{z}^{1 / 2}$ and $A_{2}$ for CDA-acetone system, concluding that the temperature coefficient of $\mathrm{A}$ is a predominant factor controlling $\mathrm{d}[\eta] / \mathrm{d} T$ ( $T$, temperature). 
Whether their conclusion for a specific CD solution can be applicable to other CD systems or not remains unsolved.

There are very few solvents suitable for molecular characterization of cellulose and then, studies on cellulose dilute solutions have been cairied out at constant temperature only in cadoxen ${ }^{16,22}$ and iron sodium tartarate $(\mathrm{FeTNa}){ }^{23}$ After finding the experimental fact that cellulose can be dissolved molecularly in aq lithium hydroxide ${ }^{24}(\mathrm{LiOH})$ and $\mathrm{NaOH}^{25}$ at around $4 . \mathrm{C}$ when cellulose has a proper supermolecular structure and an adequate dissolving procedure is employed, we $\mathrm{e}^{24}$ investigated the dilute solution properties of a cellulose- $6 \mathrm{wt} \%$ aq LiOH solution system by viscometry and the light scattering method. In that study, a significant negative coefficient of $[\eta], \mathrm{d} \ln [\eta] / \mathrm{d} T<0$, for the above system was also observed over the temperature range $-5-45^{\circ} \mathrm{C}$ as was the case of numerous $\mathrm{CD}$ solutions.

This article investigates the dilute solution properties, including $[\eta],\left\langle S^{2}\right\rangle_{z}^{1 / 2}, A_{2}$ and the weight-average molecular weight $\bar{M}_{w}$, of cellulose $-8 \mathrm{wt} \%$ aq $\mathrm{NaOH}$ solution as function of temperature over a range of $c a .0-45^{\circ} \mathrm{C}$.

\section{EXPERIMENTAL}

\section{Preparation of Cellulose Sample and Its Solutions}

The regenerated cellulose sample used in a previous paper $^{24}$ (sample code SA3, $\bar{M}_{w}=$ $8.0 \times 10^{4}$ ) was utilized for in this study. One gram of sample was dried at room temperature in vacuo for one day and immersed in 10 gram of water, stood at a temperature below $-10^{\circ} \mathrm{C}$ for one day to freeze the water. Then, the above mixture solid was defreezed and the cellulose suspended in water was obtained. This pretreatment which promotes the swelling of cellulose was very helpful to make a gel free cellulose solution. On the other hand, 15.92 gram of $\mathrm{NaOH}$ (guaranteed reagent) were mixed with 173.08 gram of distilled water to give aq $\mathrm{NaOH}$ solution, maintained at $-6^{\circ} \mathrm{C}$, to which the cellulose-water suspension was added carefully. The mixture was agitated mechanically for $5 \mathrm{~min}$ and finally a clear and transparent $0.5 \mathrm{wt}^{\%} \%\left(5.45 \times 10^{-3} \mathrm{~g} \mathrm{~cm}^{-3}\right)$ cellulose solution in $8 \mathrm{wt} \%$ aq $\mathrm{NaOH}$ solution was prepared. The solution was filtered through a sintered glass filter (grade 1) and used for the viscosity and light scattering measurements.

\section{Solution Viscosity}

The filtered cellulose solution was diluted with $8.04 \mathrm{wt} \%$ aq $\mathrm{NaOH}$ solution to give four solutions with different cellulose concentrations.

Solution viscosity was measured in a modified Ubbelohde suspension type viscometer at temperature ranging from $0.6-46^{\circ} \mathrm{C}$. The temperature was controlled to $\pm 0.01^{\circ} \mathrm{C}$. $[\eta]$ was determined using a Huggins plot.

\section{Light Scattering}

The refractive index of $8 \%$ aq $\mathrm{NaOH}$ solution $n_{0}$ was determined on a Hitachi refractometer PRA-B with an unpolarized light of wave length $633 \mathrm{~nm}$ at temperatures from 3.5 to $45^{\circ} \mathrm{C}$. For the same reason as described in the previous paper ${ }^{24}$ for cellulose- $6 \mathrm{wt}^{\mathrm{o}} \%$ aq $\mathrm{LiOH}$ solution, the specific refractive index increment under constant chemical potential $\mu$ of $\mathrm{NaOH}$ in the solutions $(\partial n / \partial c)_{\mu}(c$, concentration of polymer, $\mathrm{g} \mathrm{cm}^{-3}$ ) could not be evaluated. Then, $(\partial n / \partial c)$ at constant $\mathrm{NaOH}$ fraction in aq $\mathrm{NaOH}$, designated as $(\partial n / \partial c)_{\phi \mathrm{N}}$, was determined by a Shimadzu differential refractometer type DR-4 with an incident light of wave length $\lambda_{0}$ of $633 \mathrm{~nm}$ at temperatures in the range $10-45^{\circ} \mathrm{C}$.

Eight $\%$ aq $\mathrm{NaOH}$ solution (simply referred to as aq NaOH) was filtered through a poly(tetrafluoroethylene) (PTFE) membrane FP series (pore diameter $0.1 \mu \mathrm{m}$ ), manufactured by Sumitomo Denko Co. (Osaka) in a circulating filtration apparutus for $24 \mathrm{~h}$ and filtered three times through a PTFE membrane 
FP series (pore diameter $0.1 \mu \mathrm{m}$ ) installed in a Millipore pressure holder under atomospheric pressure.

The cellulose solution with $c=0.545 \mathrm{~g} \mathrm{~cm}^{-3}$ was centrifuged at $1 \times 10^{5} \mathrm{~g}$ for 60 minutes at $10^{\circ} \mathrm{C}$ in a Hitachi model $55 \mathrm{p}-7$ automatic preparative ultracentrifuge. The upper twothirds of the supernatant phase were carefully sucked up with a microsyringe and filtered through a PTFE membrane (pore diameter $0.45 \mu \mathrm{m}$ ) installed in a Millipore pressure holder. Then the aq $\mathrm{NaOH}$, purified as described before, was added to give cellulose solutions of five different cellulose concentrations. Each solution was filtered under atmospheric pressure at $20-27^{\circ} \mathrm{C}$ through PTFE membranes (pore diameter 0.1, 0.22, 0.3, $0.45 \mu \mathrm{m}$ ) and the last filtrate was directly transferred a cylindrical light scattering cell, which was then sealed with Parafilm "M" (manufactured by American Can Co. (U.S.A.)) in order to avoid absorption of carbondioxide from the air. The light scattering measurements for each solution were carried out successively at six different temperatures of 3.5 , 10, 26, 35, 41, and $45^{\circ} \mathrm{C}$ (controlled to $\pm 0.1^{\circ} \mathrm{C}$ ). After the experiments at a given temperature and when measurements had to be intercepted temporarily, the solution was once cooled to $4^{\circ} \mathrm{C}$ and stocked. In order to avoid gelation, all measurements were designed in the direction of rising temperature. A light scattering apparutus, DLS-700 manufactured by Otsuka Electronics (Osaka), was utilized with an incident light (vertically polarized light) of $\lambda_{0}=633 \mathrm{~nm}$. The calibration of the apparatus was done with the literature value $\mathrm{e}^{26}\left(1.184 \times 10^{-6} \mathrm{~cm}^{-1}\right)$ of reduced Rayleigh ratio of benzene. The following operating conditions were employed: Gate time 160 second, accumulation 100 times, the measuring angle $20-150^{\circ}\left(10^{\circ}\right.$ each). The data were analyzed according to Zimm's procedure to evaluate apparent $\bar{M}_{w}{ }^{*},\left\langle S^{2}\right\rangle_{z}^{1 / 2}$ and the apparent second virial coefficient $A_{2}{ }^{*}$.

\section{RESULTS AND DISCUSSION}

Figure 1 shows the plots of $\eta_{\mathrm{sp}} / c\left(\eta_{\mathrm{sp}}\right.$, specific viscosity) against $c$ for a cellulose sample code SA3-8 $\mathrm{wt} \% \mathrm{NaOH}$ solution over a wide temperature range. At each temperature the plot can be accurately represented by a straight line. [ $\eta$ ], evaluated by extrapolating $\eta_{\mathrm{sp}} / c$ to $c=$ 0 , and Huggins coefficient $k^{\prime}$, determined from

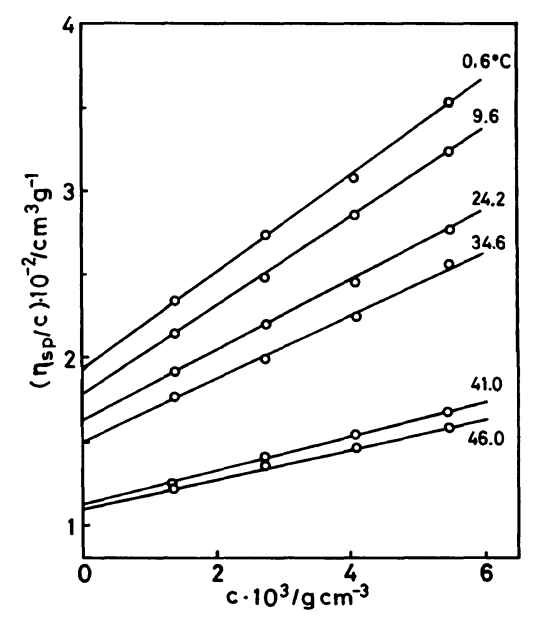

Figure 1. Plots of the ratio $\eta_{\mathrm{sp}} / c$ ( $\eta_{\mathrm{sp}}$, specific viscosity; $c$, concentration) against $c$ at various temperatures ranging from 0.6 to $46^{\circ} \mathrm{C}$.

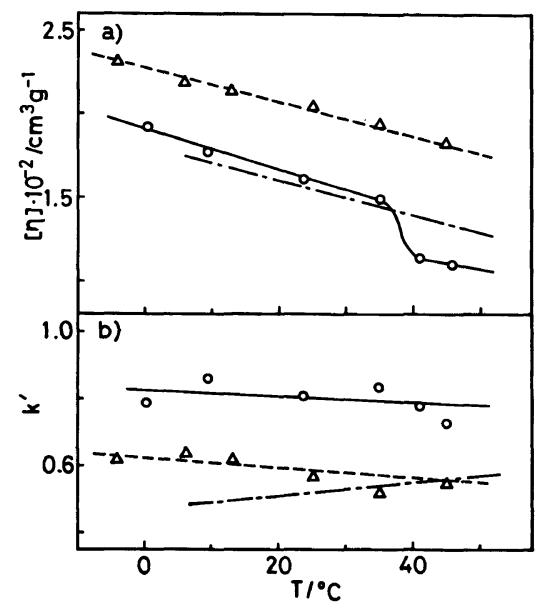

Figure 2. Plots of limiting viscosity number $[\eta]$ (a) and Huggins' constant $k^{\prime}$ (b) against temperature $T$. $\bigcirc$, cellulose $-8 \% \mathrm{NaOH}$ aq solution (solid line) (this work); $\triangle$, cellulose- $6 \%$ LiOH aq solution ${ }^{24}$ (broken line); chain line, cellulose diacetate-acetone system. ${ }^{21}$ 
the slope of the plot, are plotted as a function of temperature in Figure 2. Here, in the figure, the literature data on cellulose (sample code SA3) $-6 \mathrm{wt} \%$ aq $\mathrm{LiOH}$ solution ${ }^{24}$ (triangle) and CDA $\left(\bar{M}_{w}=9.4 \times 10^{4}\right)$-acetone ${ }^{21}$ (chain line) systems are included for comparison. Inspection of Figure 2 leads to the conclusion that $[\eta]$ of cellulose $-8 \mathrm{wt} \%$ aq $\mathrm{NaOH}$ is smaller than that of cellulose- $6 \mathrm{wt} \% \mathrm{aq} \mathrm{LiOH}$ at least in the range $0.6-46.0^{\circ} \mathrm{C}$. In the range of temperature below $35^{\circ} \mathrm{C}$, $[\eta]$ in aq $\mathrm{NaOH}$ decreases linearly with an increase in temperature as in the case of cellulose aq $\mathrm{LiOH}$ and CDA-acetone systems. $\mathrm{d}[\eta] / \mathrm{d} T$ was found to be $-1.2 \mathrm{~cm}^{3} \mathrm{~g}^{-1} \mathrm{~K}^{-1}$ for aq $\mathrm{NaOH}$, of which the absolute magnitude was slightly larger than that for aq $\mathrm{LiOH}\left(-1.02 \mathrm{~cm}^{3} \mathrm{~g}^{-1} \mathrm{~K}^{-1}\right)$ and CDA-acetone $\left(-1.01 \mathrm{~cm}^{3} \mathrm{~g}^{-1} \mathrm{~K}^{-1}\right) .[\eta]$ in aq $\mathrm{NaOH}$ decreased drastically in the range $35-41^{\circ} \mathrm{C}$, suggesting that a certain conformational change of cellulose chain might occur in this narrow temperature range. Similar change in $[\eta]$ was observed in the region of helix-coil transition of the poly $(\gamma$-benzyl L-glutamate)-dichloroacetic acid-ethylene dichloride system. ${ }^{27}$ Huggins coefficients in aq $\mathrm{NaOH}$ and aq $\mathrm{LiOH}$ are about 0.8 and 0.6 , respectively, being not so sensitive to the temperature, slightly decreasing with increaseing temperature, whereas the CDA-acetone system exhibited a positive temperature dependence of $k^{\prime}$.

Figures $3 \mathrm{a}$ and $3 \mathrm{~b}$ show the temperature dependences of $n_{0}$ and $(\partial n / \partial c)_{\phi N}$ of cellulose in aq $\mathrm{NaOH} . n_{0}$ and $(\partial n / \partial c)_{\phi \mathrm{N}}$ can be empirically represented by eq 1 and 2 , respectively.

$$
\begin{aligned}
n_{0} & =1.3535-2.17 \times 10^{-4} \quad(\mathrm{~T}-25) \\
(\partial n / \partial c)_{\phi \mathrm{N}} & =0.154-3.0 \times 10^{-4}(\mathrm{~T}-25)\left(\mathrm{cm}^{3} \mathrm{~g}^{-1}\right)
\end{aligned}
$$

Here $T$ is expressed by the ${ }^{\circ} \mathrm{C}$ unit. The value of $(\partial n / \partial c)_{\phi \mathrm{N}}$ at $25^{\circ} \mathrm{C}(0.154)$ is $c a .13 \%$ larger than that for the undialyzed cellulose (SA3)- 6 $\mathrm{wt}^{\mathrm{o}} \%$ aq $\mathrm{LiOH}$ solution system ${ }^{24}\left((\partial n / \partial c)_{\phi \mathrm{L}}=\right.$ $0.134)$ at the same temperature. The CDA-

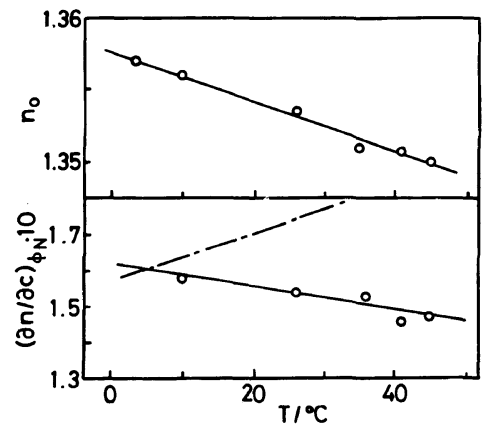

Figure 3. Refractive index $n_{0}$ of $8 \% \mathrm{NaOH}$ aq solution (a) and refractive index increment $\partial \mathrm{n} / \partial \mathrm{c}$ of cellulose $-8 \%$ $\mathrm{NaOH}$ aq solution (circle and solid line) and cellulose diacetate-acetone system ${ }^{21}$ (broken line) (b) as a function of temperature $T$.

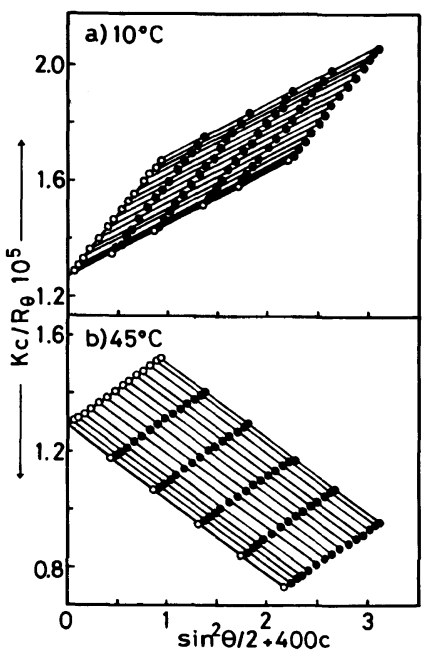

Figure 4. Zimm plots of cellulose- $8 \% \mathrm{NaOH}$ aq solution system at temperature of $10^{\circ} \mathrm{C}$ (a) and $45^{\circ} \mathrm{C}$ (b). - experimental data; $\bigcirc$, extrapolated value from the experimental data at scattering angle $\theta=0$ and a concentration $C=0$.

acetone system has a positive temperature dependence of $(\partial n / \partial c),{ }^{21}$ whereas celluloseaq $\mathrm{NaOH}$ system shows a negative temperature coefficient of $(\partial n / \partial c)_{\phi N}$.

Figures $4 \mathrm{a}$ and $4 \mathrm{~b}$ show some typical Zimm plots of the cellulose sample code SA3 in aq $\mathrm{NaOH}$. At any temperature of measurements ranging $3.5-45^{\circ} \mathrm{C}$, no significant distortion was observed in the Zimm plots. This means that the solutions prepared in this study 
Table I. Results of light scattering measurements on cellulose- $8 \% \mathrm{NaOH}$ aq solution and hydro- and thermo-dynamic parameters in $8 \% \mathrm{NaOH}$ aq solution at temperatures ranging from 3.5 to $45^{\circ} \mathrm{C}$

\begin{tabular}{|c|c|c|c|c|c|c|c|c|c|}
\hline \multirow{3}{*}{$\begin{array}{c}\text { Temp } \\
{ }^{\circ} \mathrm{C}\end{array}$} & \multicolumn{7}{|c|}{ Light scattering } & \multirow{2}{*}{\multicolumn{2}{|c|}{$\begin{array}{c}\begin{array}{c}\text { Hydro-, thermo-dynami } \\
\text { parameters }\end{array} \\
8 \% \mathrm{NaOH} \text { aq solution }\end{array}$}} \\
\hline & \multicolumn{3}{|c|}{$8 \% \mathrm{NaOH}$ aq solution } & \multicolumn{3}{|c|}{$6 \% \mathrm{LiOH}$ aq solutiona } & \multirow{2}{*}{$\frac{\text { Cadoxen }^{\mathrm{a}}}{\begin{array}{c}\bar{M}_{w} \\
\times 10^{-4}\end{array}}$} & & \\
\hline & $\begin{array}{c}\bar{M}_{w}{ }^{*} \\
\times 10^{-4}\end{array}$ & $\begin{array}{c}\left\langle S^{2}\right\rangle_{z}^{1 / 2 b} \\
\times 10^{6}\end{array}$ & $\begin{array}{l}A_{2}{ }^{* \mathrm{c}} \\
\times 10^{4}\end{array}$ & $\begin{array}{c}\bar{M}_{w}{ }^{*} \\
\times 10^{-4}\end{array}$ & $\begin{array}{l}\left\langle S^{2}\right\rangle_{z}{ }^{1 / 2} \\
\quad \times 10^{6}\end{array}$ & $\begin{array}{l}A_{2}{ }^{*} \\
\times 10^{4}\end{array}$ & & $\begin{array}{c}\Phi \\
\times 10^{-22}\end{array}$ & $\alpha_{s}$ \\
\hline 3.5 & 8.10 & 3.66 & $4.79(4.91)^{d}$ & - & - & - & - & 4.14 & 1.005 \\
\hline 10 & 7.89 & 3.61 & 3.75 & - & - & - & - & 3.95 & 1.004 \\
\hline 25 & - & - & - & 12.1 & 3.25 & 11.0 & $(8.0)^{\mathrm{e}}$ & - & - \\
\hline 26 & 7.89 & 3.14 & 3.33 & - & - & - & - & 5.46 & 1.006 \\
\hline 35 & 7.98 & 3.01 & 2.75 & - & - & - & - & 5.55 & 1.005 \\
\hline 41 & 7.98 & 2.69 & -0.58 & - & - & - & - & 6.10 & 0.999 \\
\hline 45 & 7.81 & 2.64 & -3.06 & - & - & - & - & 6.28 & 0.992 \\
\hline
\end{tabular}

${ }^{\mathrm{a}}$ Reference $24 .{ }^{\mathrm{b}} \mathrm{cm}$. ${ }^{\mathrm{c}} \mathrm{cm}^{3} \mathrm{molg}^{-1}, A_{2}{ }^{*} \simeq A_{2}$, except $3.5^{\circ} \mathrm{C}$. $\quad{ }^{\mathrm{d}}$ True $A_{2}$.

e Estimated value using light scattering data on two dialysed cellulose-cadoxen solutions.

had no undissolved material or gel over a wide range of measuring temperature.

Table I summarizes $\bar{M}_{w}{ }^{*},\left\langle S^{2}\right\rangle_{z}^{1 / 2}$ and $A_{2}{ }^{*}$ of cellulose in aq $\mathrm{NaOH}$, all evaluated from the Zimm plots. Here, the above quantities at $3.5^{\circ} \mathrm{C}$ were determined using the value of $(\partial n / \partial c)_{\phi N}$ calculated by eq 2 .

Figure 5a shows the temperature dependence of $\bar{M}_{w}{ }^{*}$. Evidently, $\bar{M}_{w}{ }^{*}$ of cellulose dissolved in aq $\mathrm{NaOH}$ remains almost constant $\left(\sim 7.9 \times 10^{4}\right)$ above $10^{\circ} \mathrm{C} . \bar{M}_{w}{ }^{*}$ of the same sample in aq $\mathrm{LiOH}$ (undialyzed) at $25^{\circ} \mathrm{C}$ was $1.2 \times 10^{524}$ and is shown as the filled circle in the figure. This value is 1.5 times larger than that in aq NaOH. $\bar{M}_{w}$ for cellulose (SA3) in cadoxen $\left(8 \times 10^{4}\right)$, indirectly evaluated by linear interpolation of two $\bar{M}_{w}$ data directly determined by the light scattering method for two other samples in dialyzed cadoxen, ${ }^{24}$ is in fairly good agreement with $\bar{M}_{w}{ }^{*}$ in aq $\mathrm{NaOH}$. Then, we can consider $\bar{M}_{w}^{*} \simeq \bar{M}_{w}$ in aq $\mathrm{NaOH}$. In other words, the selective adsorption does not occur essentially above $10^{\circ} \mathrm{C}$ for cellulose-aq $\mathrm{NaOH}$ system, but this can never be ignored for cellulose-aq $\mathrm{LiOH}$ system. We can also conclude that cellulose dissolves molecularly into aq $\mathrm{NaOH}$, at least over a tem-

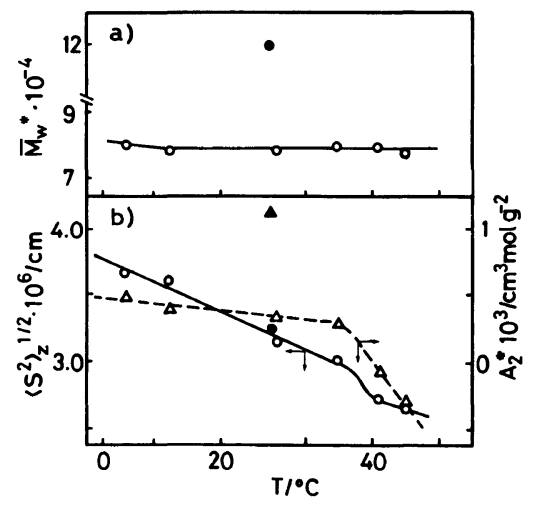

Figure 5. Plots of apparent weight-average molecular weight $\bar{M}_{\mathrm{w}}{ }^{*}$ (a) and apparent second virial coefficient $A_{2}{ }^{*}$ and $z$-average radius of gyration $\left\langle S^{2}\right\rangle_{z}{ }^{1 / 2}$ (b) against temperature $T$. Open marks, cellulose- $8 \% \mathrm{NaOH}$ aq solution and closed marks, cellulose- $6 \% \mathrm{LiOH}$ aq solution system. ${ }^{24}$

perature range of $10-45^{\circ} \mathrm{C}$ and the discussion on "solubility" of cellulose in aq $\mathrm{NaOH}$ by Kamide $e t$ al. $^{25}$ is absolutely acceptable.

Now we can evaluate a parameter representing selective adsorption, $\Gamma$, quantitatively from the equation ${ }^{28}$

$$
\left.\Gamma=\left\{\bar{M}_{w}{ }^{*} / \bar{M}_{w}\right)^{1 / 2}-1\right\} d_{\mathrm{N}}(\partial n / \partial c)_{\phi \mathrm{N}} /\left(\partial n_{0} / \partial \phi_{\mathrm{N}}\right)
$$


to be 0.007 at $3.5^{\circ} \mathrm{C}$, where $d_{\mathrm{N}}$ is the density of $8 \mathrm{wt} \%$ aq $\mathrm{NaOH}$ solution (ca. 1.09) and $\partial n_{0} / \partial \phi_{\mathrm{N}}$ is an increment of refractive index of aq $\mathrm{NaOH}\left(0.31 \mathrm{~cm}^{3} \mathrm{~g}^{-1}\right.$ at $3.5^{\circ} \mathrm{C}$ near $8 \mathrm{wt} \%$ $\mathrm{NaOH}$ concentration). $\Gamma$ of cellulose in aq $\mathrm{NaOH}$ is almost $10 \%$ of those of cellulose in aq $\mathrm{LiOH}$ at $25^{\circ} \mathrm{C}^{29}$ (i.e., $\Gamma=0.095$ for $\bar{M}_{w}=$ $5.26 \times 10^{4}$ and 0.126 for $\bar{M}_{w}=1.2 \times 10^{5}$ ).

Figure $5 \mathrm{~b}$ shows the temperature dependence of $A_{2}{ }^{*}$ (unfilled triangle) and $\left\langle S^{2}\right\rangle_{z}^{1 / 2}$ (unfilled circle) of cellulose in aq $\mathrm{NaOH}$.

The true second virial coefficient $A_{2}$ can be calculated from $A_{2}{ }^{*}$ by $^{28}$

$$
A_{2}=\left(\bar{M}_{w}^{*} / \bar{M}_{w}\right) A_{2}{ }^{*}
$$

Using eq $4 A_{2}=4.91 \times 10^{-4} \mathrm{~cm}^{3} \mathrm{molg}^{-1}$ was obtained at $3.5^{\circ} \mathrm{C}$ and is shown in parenthesis in the fourth column of Table I. Of course, at the temperature equal to or above $10^{\circ} \mathrm{C}, A_{2}{ }^{*}$ can be regarded as $A_{2}$, because $\bar{M}_{w}{ }^{*} \simeq \bar{M}_{w}$ holds. For comparison, the $A_{2}$ data on cellulose (sample code SA3)-aq $\mathrm{LiOH}$ at $25^{\circ} \mathrm{C}$ are shown. The cellulose-aq $\mathrm{NaOH}$ system has a remarkably smaller $A_{2}$ than the celluloseaq $\mathrm{LiOH}$ system, suggesting that aq $\mathrm{NaOH}$ is poor compared with aq $\mathrm{LiOH}$. The temperature dependence of $A_{2}$ for cellulose-aq $\mathrm{NaOH}$ system can be approximately represented by two straight lines; with an increase in the temperature below $35^{\circ} \mathrm{C}, A_{2}$ decreases slowly, but above $35^{\circ} \mathrm{C} A_{2}$ decreases remarkably, becoming zero at $T \simeq 40^{\circ} \mathrm{C}$. In other words, the 8 $\mathrm{wt} \%$ aq $\mathrm{NaOH}$ system is a Flory theta solvent found for cellulose. $\left\langle S^{2}\right\rangle_{z}^{1 / 2}$ decreases also with an increase in temperature. A decrease in $\left\langle S^{2}\right\rangle_{z}^{1 / 2}$ with temperature is significantly larger in the range $35 \sim 41^{\circ} \mathrm{C}$ than those in other temperature ranges (i.e., $5 \leq T \leq 35^{\circ} \mathrm{C}$ and $T \geq 41^{\circ} \mathrm{C}$ ). The value of $\left\langle S^{2}\right\rangle_{z}^{1 / 2}$ of the cellulose (SA3)-aq $\mathrm{NaOH}$ system at $26^{\circ} \mathrm{C}$ is about $4 \%$ smaller than that of the same sample (SA3)aq LiOH system at $25^{\circ} \mathrm{C}$. $\left\langle S^{2}\right\rangle_{z}^{1 / 2}$ of celluloseaq $\mathrm{NaOH}$ at $40^{\circ} \mathrm{C}$ (i.e., the unperturbed $z$ average radius of gyration, $\left.\left\langle S^{2}\right\rangle_{z, o}^{1 / 2}\right)$ was estimated, from Figure $5 \mathrm{~b}$, to be $2.77 \times 10^{-6} \mathrm{~cm}$.

Flory viscosity parameter $\Phi$ is defined by

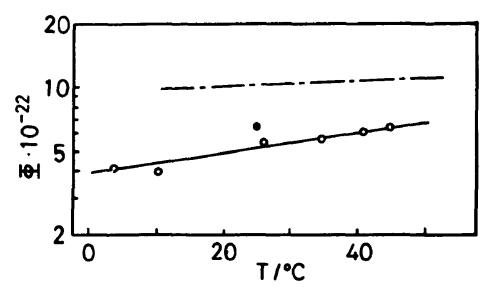

Figure 6. Plots of Flory's viscosity parameter $\Phi$ against temperature $T$. $\bigcirc$ and solid line, cellulose- $8 \%$ $\mathrm{NaOH}$ aq solution; 9 , cellulose- $6 \% \mathrm{LiOH}$ aq solution ${ }^{24}$ and chain line; cellulose diacetate-acetone system. ${ }^{21}$

$$
\Phi=q_{w, z}[\eta] \bar{M}_{w} /\left(6\left\langle S^{2}\right\rangle_{z}\right)^{3 / 2}
$$

Here, $q_{w, z}$ is the polymolecularity correction factor, prerequisiting the molecular weight distribution (MWD) function and breadth of MWD of the sample. The literature data ${ }^{16,22}$ suggest that when the acid-hydrolysis of cellulose proceeds to a greater extent, the products have $\bar{M}_{w} / \bar{M}_{n}=2$. Then, in this study we estimated $q_{w, z}(=1.955)$ assuming the SchulzZimm distribution for MWD of sample code SA 3 and 2 for its $\bar{M}_{w} / \bar{M}_{n}$. In the ninth column of Table I, the values of $\Phi$ calculated by eq 5 from $[\eta],\left\langle S^{2}\right\rangle_{z}^{1 / 2}$ and $\bar{M}_{w}$ data are summarized. Figure 6 shows the plot of $\Phi v s$. temperature. In the figure, the data point for celluloseaq LiOH is included. The $\Phi$ value for cellulose-aq $\mathrm{NaOH}$, including the value at $40^{\circ} \mathrm{C}$ (theta solvent), is slightly smaller than that for cellulose-aq $\mathrm{LiOH}$ and is only $1 / 5$ the theoretical value for the unperturbed nondraining chain $\left(2.87 \times 10^{23}\right)$. This means that the cellulose chain is partially free draining in aq $\mathrm{NaOH}$, as in the case of cellulose in aq $\mathrm{LiOH}^{24}$ and various cellulose derivatives in solvents. ${ }^{1,30,35} \Phi$ for cellulose-aq $\mathrm{NaOH}$ increases monotonically with temperature as found for $\mathrm{CDA}$-acetone system. $\mathrm{d} \ln \Phi / \mathrm{d} T$ was found to be $1.0 \times 10^{-2} \mathrm{deg}^{-1}$ for celluloseaq $\mathrm{LiOH},{ }^{24}$ which is 3.5 times larger than that $\left(2.8 \times 10^{-3} \mathrm{deg}^{-1}\right)$ for CDA-acetone. ${ }^{21}$

The penetration function $\psi$ is defined by ${ }^{31}$

$$
\begin{gathered}
\psi \equiv \bar{z} h_{0}(\bar{z})=7.45 \times 10^{-26} A_{2} \bar{M}_{w}{ }^{2} /\left\langle S^{2}\right\rangle_{w}^{1 / 2} \\
\text { with } \bar{z}=z / \alpha_{s}{ }^{3}
\end{gathered}
$$


$z$ is the excluded volume effect parameter and $\alpha_{\mathrm{s}}\left(\equiv\left\langle S^{2}\right\rangle_{w}^{1 / 2}\left\langle S^{2}\right\rangle_{w, o}^{1 / 2}\right.$; subscripts $w$ and $o$ denote the weight average and unperturbed state, respectively) is the linear expansion factor. According to the theory of Kurata-FukatsuSotobayashi-Yamakawa, ${ }^{32} \bar{z} h_{0}(\bar{z})$ in eq 6 is a function of $\bar{z}$, given by

$$
\bar{z} h_{0}(\bar{z})=(1 / 5.047)\left\{1-(1+0.683 \bar{z})^{-7.39}\right\}
$$

In the vicinity of $z \simeq 0$, the following relation holds between $z$ and $\alpha_{\mathrm{s}}^{33}$

$$
\alpha_{\mathrm{s}}^{3}=1+1.78 z
$$

Combining eq 6-9 enables us to estimate $\alpha_{\mathrm{s}}$, when $\alpha_{\mathrm{s}}$ is not far from unity, using the light scattering data. The tenth column of Table I lists the $\alpha_{\mathrm{s}}$ values determined thus. Here, $\left\langle S^{2}\right\rangle_{z}^{1 / 2}$ was converted to $\left\langle S^{2}\right\rangle_{w}^{1 / 2}$, assuming the Schulz-Zimm distribution and $\bar{M}_{w} / \bar{M}_{w}=$ 2. $\alpha_{\mathrm{s}}$ of cellulose in aq $\mathrm{NaOH}$ solution below $35^{\circ} \mathrm{C}$ lies between 1.00 and 1.01 almost independent of temperature. We can conclude that the excluded volume effect is extremely small in the cellulose-aq $\mathrm{NaOH}$ system even below $35^{\circ} \mathrm{C}$.

The unperturbed chain dimension $A$ is generally given by

$$
A=\left(6\left\langle S^{2}\right\rangle_{o, w} / \bar{M}_{w}\right)^{1 / 2}
$$

Equation 10 is valid only when the unperturbed chain is Gaussian and is only approximately valid when the unperturbed chain is not Gaussian, but the extent of departure from the Gaussian nature is not remarkable. Although, in the strict sense, the Gaussian nature of cellulose dissolved in aq $\mathrm{NaOH}$ sclution has not been experimentally confirmed yet, it is well-known that the cellulose chain behaves as a Gaussian chain in celluloseaq $\mathrm{LiOH}$ systems and we can apply eq 10 for cellulose in aq $\mathrm{NaOH}$ solution. Here, $\left\langle S^{2}\right\rangle_{o, w}$ was evaluated from $\left\langle S^{2}\right\rangle_{z}$ and $\alpha_{s}$ (method $2 \mathrm{~B}^{1}$ ). Table II summarizes the $\mathrm{A}$ values estimated thus at $25^{\circ} \mathrm{C}$ together with the literature data for cellulose in aq $\mathrm{LiOH},{ }^{24}$ cadoxen $^{16}$ and FeTNa. ${ }^{23}$
Table II. - Unperturbed chain dimension $A$ estimated using method $2 \mathbf{B}^{1}$, conformation parameter $\sigma$, and characteristic ratio $C_{\infty}$ of cellulose in various solvents at $25^{\circ} \mathrm{C}$

\begin{tabular}{lcccc}
\hline \multirow{2}{*}{ Solvent } & \multicolumn{1}{c}{$A$} & & $C_{\infty}$ \\
\cline { 2 - 3 } & $\times 10^{8} / \mathrm{cm}$ & & $\times 10^{-1}$ \\
\hline $8 \% \mathrm{NaOH}$ aq solution & 2.2 & 3.6 & 3.14 \\
$6 \% \mathrm{LiOH}$ aq solution & & & & \\
Cadoxen $^{\mathrm{a}}$ & 2.2 & & 3.6 & 2.97 \\
FeTNa $^{\mathrm{c}}$ & $1.9^{\mathrm{b}}$ & $3.1^{\mathrm{b}}$ & - \\
\hline
\end{tabular}

a Reference 24.

b Value at $\bar{M}_{w}=8 \times 10^{4}$ estimated using the data in ref 16.

c Iron sodium tartarate.

d Value at $\bar{M}_{w}=8 \times 10^{4}$ estimated using the data in ref 23.

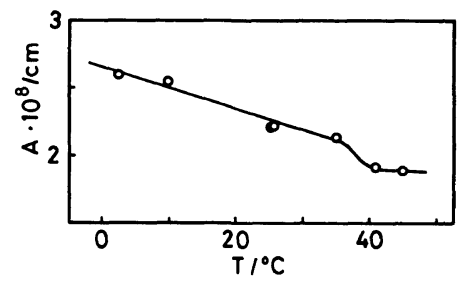

Figure 7. Plots of unperturbed chain dimension $A$ of cellulose aq alkaline solvents against temperature $T$. $\bigcirc$ and solid line, $8 \% \mathrm{NaOH}$ aq solution; $\mathrm{O}, 6 \% \mathrm{LiOH}$ aq solution. ${ }^{24}$

Figure 7 shows the temperature dependence of $A$. The temperature dependence of $A$ is almost the same as that of $\left\langle S^{2}\right\rangle_{z}^{1 / 2}$ below $35^{\circ} \mathrm{C}$, becuase $\alpha_{\mathrm{s}}$ is practically independent of the temperature. In the figure, the value of $A$ for cellulose in aq $\mathrm{LiOH}$ at $25^{\circ} \mathrm{C}$ is shown by the filled circle. $A$ in aq $\mathrm{NaOH}$ is nearly the same as that in aq $\mathrm{LiOH}$.

In Table II are shown the conformation parameter $\sigma\left(\equiv A / A_{\mathrm{f}}, A_{\mathrm{f}}\right.$ is $A$ of hypothetical free rotating chain) and the characteristic ratio $C_{\infty}\left(\equiv A_{\infty}^{2} M_{\mathrm{b}} / l^{2}, A_{\infty}\right.$ is $A$ for $M=\infty, M_{\mathrm{b}}$, the molecular weight per skeletal bond, $l$, the mean bond length). The flexibility of cellulose chain in aqalkali solutions lies between those in cadoxen and iron sodium tartarate. Comparing the values of $\sigma$ for cellulose in 
these solvents with those of typical flexible polymers, ${ }^{1}$ we can conclude that the cellulose chain dissolved in any solvent belongs to a category of semi-flexible chains.

$[\eta]$ can be represented in the form ${ }^{34}$

$$
[\eta]=6^{3 / 2} \Phi\left(\left\langle S^{2}\right\rangle_{o, w}^{3 / 2} / \bar{M}_{w}\right) \alpha_{s}{ }^{3}
$$

Equation 11 can be readily transformed by differentiating the logarithm of the both side of the equation into

$$
\begin{aligned}
\mathrm{d} \ln [\eta] / \mathrm{d} T= & \mathrm{d} \ln \Phi / \mathrm{d} T \\
& +1.5 \mathrm{~d} \ln \left(\left\langle S^{2}\right\rangle_{o, w} / \bar{M}_{w}\right) / \mathrm{d} T \\
& +3 \mathrm{~d} \ln \alpha_{\mathrm{s}} / \mathrm{d} T
\end{aligned}
$$

Each term in the right hand side of eq 12 can be estimated for cellulose-aq $\mathrm{NaOH}$ below $35^{\circ} \mathrm{C}$

$$
\begin{gathered}
\mathrm{d} \ln [\eta] / \mathrm{d} T=-7.42 \times 10^{-3} \\
\mathrm{~d} \ln \Phi / \mathrm{d} T=1.0 \times 10^{-2} \\
\mathrm{~d} \ln \left(\left\langle S^{2}\right\rangle_{o, w} / \bar{M}_{w}\right) \mathrm{d} T=-1.26 \times 10^{-2} \\
\mathrm{~d} \ln \alpha_{\mathrm{s}} / \mathrm{d} T \simeq 0
\end{gathered}
$$

Putting the values in eq $14-16$ into the right hand side of eq 12 , we obtain $-8.90 \times 10^{-3}$, which agrees fairly well with the experimental $\mathrm{d} \ln [\eta] / \mathrm{d} T$ value $\left(=-7.42 \times 10^{-3}\right)$. Inspection of eq 14-16 shows that the temperature dependence of the unperturbed chain dimension is a main factor governing the negative temperature coefficient of $[\eta]$ for celluloseaq $\mathrm{NaOH}$, as was found by Suzuki et al. ${ }^{21}$ for the CDA-acetone system.

The remarkable decrease in $[\eta]$ at the temperature range of $35-41^{\circ} \mathrm{C}$ can also be explained by the large negative temperature dependence of the unperturbed chain dimensions. Kamide and Saito ${ }^{35}$ indicated that there exists a strong correlationship between the number of solvent molecules solvated per a pyranose ring at infinite dilution $s_{0}$ and $A$ for the CDA-acetone system and the solvation makes the cellulose chain rigid. The negative temperature dependence of $A$, observed also for cellulose-aq $\mathrm{NaOH}$ system, can be speculated to be due to the negative temperature dependence of the solvation.

The conclusions reached in the previous paper $^{24}$ for cellulose-aq LiOH have not changed for cellulose-aq $\mathrm{NaOH}$ systems:

(1) Cellulose dissolves molecularly in aq $\mathrm{NaOH}$

(2) Cellulose is semi-flexible in aq $\mathrm{NaOH}$

(3) The excluded volume effect is small or zero (at $40^{\circ} \mathrm{C}$ )

(4) Partially free drainage effect is not negligibly small.

\section{REFERENCES AND NOTES}

1. K. Kamide and Y. Miyazaki, Polym. J., 10, 409 (1978).

2. K. Kamide and M. Saito, Eur. Polym. J., 17, 1049 (1981).

3. K. Kamide and M. Saito, Eur. Polym. J., 18, 661 (1982).

4. V. P. Shanbhag and J. Öhman, Ark. Kemi, 29, 163 (1968).

5. H. Suzuki, Y. Muraoka, M. Saito, and K. Kamide, Eur. Polym. J., 18, 831 (1982).

6. H. Suzuki, Y. Muraoka, M. Saito, and K. Kamide, Br. Polym. J., 14, 23 (1982).

7. D. A. Clibbins and A. Greaks, J. Text. Inst., 19, T77 (1928).

8. F. Howlett, E. Minshall, and A. R. Urquhart, $J$. Text. Inst., 35, T133 (1944).

9. L. Mandelkern and P. J. Flory, J. Am. Chem. Soc., 74, 2517 (1957).

10. R. S. J. Manley, Ark. Kemi, 9, 519 (1956).

11. P. J. Flory, O. K. Spurr Jr., and D. K. Carpenter, $J$. Polym. Sci., 27, 231 (1958).

12. W. R. Moore and A. M. Brown, J. Colloid Sci., 14, 1 (1959).

13. W. R. Moore and A. M. Brown, J. Colloid Sci., 14, 343 (1959).

14. W. R. Krigbaum and L. H. Sperling, J. Phys. Chem., 64, 99 (1960).

15. W. R. Moore and G. D. Edge, J. Polym. Sci., 47, 469 (1960).

16. D. Henley, Ark. Kemi, 18, 327 (1961).

17. K. Kamide, K. Ohno, and T. Kawai, Kohbunshi Kagaku (Japan), 20, 151 (1963).

18. W. Brown, D. Henley, and J. Öhman, Makromol. Chem., 64, 49 (1963).

19. W. Brown and D. Henley, Makromol. Chem., 75, 174 (1964).

20. V. P. Shanbhag, Ark. Kemi, 29, 1 (1968). 
21. H. Suzuki, Y. Miyazaki, and K. Kamide, Eur. Polym. J., 16, 703 (1980).

22. W. Brown and R. Wirkström, Eur. Polym. J., 1, 1 (1965)

23. V. Valtassari, Makromol. Chem., 150, 117 (1971).

24. K. Kamide and M. Saito, Polym. J., 18, 569 (1986).

25. K. Kamide, K. Okajima, T. Matsui, and K. Kowsaka, Polym. J., 16, 858 (1984).

26. E. R. Pike, W. R. M. Pomeroy, and J. M. Vaughan, J. Chem. Phys., 62, 3188 (1975).

27. T. Teramoto and H. Fujita, Advan. Polym. Sci., 18, 65 (1975)

28. M. B. Huglin, "Light Scattering from Polymer Solutions," M. B. Huglin Ed., Academic Press, London, 1972, pp 192, Chapter 6.
29. Note that $\Gamma$ value calculated for $6 \mathrm{wt} \%$ aq $\mathrm{LiOH}$ in the ref 24 should be multiplied by the density of $6 \mathrm{wt}^{\mathrm{o}} \%$ aq $\mathrm{LiOH}$ (1.08). We thank Dr. Huglin for his comment.

30. K. Kamide and M. Saito, Polym. J., 14, 517 (1982).

31. See, for example, M. Kurata, "Industrial Chemistry of High Polymers," Vol. III, Modern Industial Chemistry No. 18, Asakura, Tokyo, 1975, Chapter 4.

32. M. Kurata, M: Fukatsu, H. Sotobayashi, and H. Yamakawa, J. Chem. Phys., 41, 139 (1964).

33. M. Fixman, J. Chem. Phys., 36, 3123 (1962).

34. P. J. Flory and T. G. Fox, J. Am. Chem. Soc., 73, 1904 (1951).

35. K. Kamide and M. Saito, Eur. Polym. J., 20, 903 (1984). 